\title{
Factors influencing financial inclusion in India
}

\author{
Mansha Rafiq and Abideen Adewale \\ IIUM Institute of Islamic Banking and Finance \\ International Islamic University \\ Malaysia
}

\begin{abstract}
In the modern era, financial institutions serve as facilitators of economic progress and advancement. It is, therefore, necessary that people have equitable access to these financial institutions and the services they offer especially in emerging economies like India. Notwithstanding that the Indian banking sector has grown tremendously over the years in terms of performance and outreach, a large number of people have limited or zero access to the financial services. Financial Inclusion thus emerges as a necessity for it is equally beneficial to the banks as well as to the unserved population vis-a-vis the provision of new avenues for the former and financial services for the latter. In this study, we used panel data covering Indian states over a period of five years, from 2009 to 2013 , to assess the factors influencing financial inclusion in the country. This study found that distinct state-effect is prevalent among the Indian states. Further, the number of factories as a proxy for industrialization and outstanding credit as a proxy for loans and advancements significantly reveal that income and employment generating schemes must be launched by the Government of India and the Central Bank of India keeping in mind the underprivileged lot.
\end{abstract}

Key words: Financial services, Banks, Panel data.

\section{INTRODUCTION}

Even though its consequences may be similar, the incidence of lack of financial inclusion is essentially multidimensional [1]. For instance, Leyshon and Thrift [2] described the manifestation of the lack of financial inclusion in the context of those practices that avert various individuals or social groups from accessing formal financial services. Sinclair [3] similarly described the consequences of the lack of financial inclusion in the context of the outcome of various problems in relation to access, prices, conditions et cetera related to financial services as a result of adverse practices or perception among people. Viewing it from a positive perspective, the Chairman of the 'Committee of Financial Inclusion in India' Dr. C. Rangarajan defines financial inclusion, "as the process of ensuring access to financial services to timely and adequate credit where needed by vulnerable groups such as weaker sections and low income groups at an affordable cost" (Rangarajan Committee, 2008)

From the point of view of a financial institution, financial inclusion concerns the spread of its undertakings among diverse segments of the populace. The field of these undertakings vary across various countries some being quite large in extent. For example in the UK, access to banking, affordable credit and face-to-face money advice are the chief dimensions. Alongside these major factors, in the developing countries like India priority sector such as agricultural and economic backward classes in the society should ideally be considered for these formal financial services.

Efforts must be made to make finance accessible to the underprivileged sections of the society in order to lift their financial condition and standard of life [4]. In India however, poverty is getting concentrated in the poorer states making the consequences of financial exclusion even more serious. Banks in such a scenario have a critical role to play, by acting as allocators for investment purposes, production purposes and as well as mobilisers of savings. For example, credit is provided to the entrepreneurs for initiating new commercial activities which may in

Corresponding Author: Mansha Rafiq, IIUM Institute of Islamic Banking and Finance, International Islamic University Malaysia. 
turn lead to economic growth. Moreover remittance facilities along with other products related to payments are provided by the retail commercial banks. Therefore, essentially by acting as of change, banks hold tremendous potential when it comes to redistribution of wealth among the society.

Nevertheless, it is off-putting to note that these products and services proposed by the banking sector are accessible to a very few in spite of inclusive banking initiatives in the country via actions such as nationalizing of banks, by creating legal rural banks, cooperative movement, et cetera. Subhbarao [5] points out in his study that only 30,000 centres are covered by commercial banks out of the 600,000 inhabitations in India [6]. There is a massive rural urban divide in terms of financial access indicators, as two thirds of the population resides in rural areas, it is therefore deprived of financial services and products.

With regard to volume and complexity the banking industry in India has seen tremendous growth throughout these years. Notwithstanding, the underprivileged sections of the society in spite of all the improvements in the financial sector are alien to all these services and facilities. This shouldn't be the case, as there is extensive improvement in capacities related to financial viabilities and competitiveness. There are still 145 million unbanked individuals residing in India and the banking system is unable to keep pace with the increase in number as the population per branch reduced from 14000 in 1991 to 13,503 in 2011 and to a low of 12.921 in 2013 [7]. Nearly half of the people $(55 \%)$ possess deposit accounts and sadly India's demand for microfinance remains the highest in the world. With efforts being made both by the Government and the RBI there are about 100 million 'no-frill' accounts, or accounts with zero or minimal balance and small overdraft facilities for the poor. Unfortunately, $80-90 \%$ of them are neither operated by the account holders nor pursued by the bankers, thereby staying dormant. This idea is criticized by many and labelled as a 'jobless growth', as much of the excess labor is absorbed in unproductive agriculture. In spite of the exertions laid by the authorities which is appreciated on many grounds, the status of financial inclusion in other developed and emerging economies is still higher when compared to India.

Financial inclusion in India

CRISIL Inclusix which is an index that measures the progress of financial inclusion in India, in their research combines three very important and critical parameters required for basic banking services available to all. These include bank penetration, deposit penetration and credit penetration which are all combined together in one single metric. The findings show all-India score of 40.1 out of 100 which is relatively low and hence clearly shows the underdevelopment for providing banking services across all the states in India. According to the study, deposit penetration is the main drive to attaining financial inclusion in India. The number of loan accounts are comparatively very low when compared to deposit accounts. However, when compared to the past years performance, the score has improved commendably. This improvement is attributed to the increased number of borrowings, i.e. higher credit penetration combined with improvement in banking penetration. The southern region is the most financially included with highest credit penetration while the eastern region is the least financially included. A plausible reason could be the higher literacy rate in the southern region as compared to the eastern and the north-eastern regions. The Indian economy is accelerating at a tremendous pace and overtook the Japanese economy in 2011, thereby ranks number third after Unites States and China in terms of purchasing power parity. ${ }^{1}$ A lot still needs to be done on the rural front to overcome regional imbalances, gender gap and the digital divide. Ninety percent of the workforce in India which also contribute to $50 \%$ of national product, is looming on the edges of financial exclusion. About $15 \%$ to the GDP comes via agriculture, yet credit to farmers is declining, therefore making half of the population deprived of basic needs of credit [28]. Moreover, the gender gap in agricultural credit is massive and increase in feminization of agriculture with female agricultural labour on an escalation. Over the past two decades the share of bank accounts of small farmers has declined and little or no correlation can be observed between the use of no frill accounts and the subsequent programmes launched to curb the issue- none have shown to boost financial inclusion in a very healthy trend ${ }^{2}$

While it is an intimidating task in size and scope, financial inclusion is as much a boundless social and

\footnotetext{
${ }^{1}$ Recent reports by the IMF and World Bank states that India has overtaking China and is now the second largest economy in the world.

${ }^{2}$ http://www.skoch.in/images/Financial\%20Inclusion $\% 20$ State $\% 20$ of $\% 20$ the
} $\% 20$ Sector\%20Report.pdf (accessed 20.06.13). 
business opportunity as a necessity to bridge widening socio-economic gaps archetypal of countries where financial exclusion persists. As such, the objective of this paper is to investigate the determinants of financial inclusion in India on a state-wise basis. This is with the intent of unraveling if a state-wide effect exists vis-à-vis financial inclusion determinants and to suggest policy recommendations contingent upon findings. The remainder of the paper comprises the methodology, results, conclusion and recommendation.

\section{DATA DESCRIPTION AND METHODOLOGY}

Data description and key variables

The study comprises of state-wise balanced panel data for five years from 2009 to 2013. Annual data of 30 regions in total is included in the study which comprises of 26 Indian states and four union territories. Due to the unavailability of data the rest of the regions in India such as Arunachal Pradesh, Mizoram, Telangana, Dadra and Nagar Haveli, Daman and Diu and Lakshadweep have not been included. Therefore, this study has a sample size of 1503, one dependent variable and eight independent variables. Data has been obtained from the Basic Statistical Returns of Scheduled Commercial Banks in India acquired from the website of the Reserve Bank of India. The basic empirical model for determining the factors affecting financial inclusion is written in the equation below:

\section{$\operatorname{lnFIDit}=\alpha+\beta 1 \ln B$ Cit $+\beta 2 \ln M A C i t+\beta 3 \ln F A C i t+$ $\beta 4 \ln O C$ it $+\beta 5 \ln C D R i t+\beta 6 \ln N S D P i t+$ $\beta 7 \ln$ GRit $+\beta 8 \ln N O F i t+\varepsilon i t$}

Where,

FID = number of deposits as a proxy for financial inclusion

$\mathrm{BC}=$ number of bank branches

$\mathrm{MAC}=$ number of male accounts

$\mathrm{FAC}=$ number of female accounts

$\mathrm{OC}=$ outstanding credit

$\mathrm{CDR}=$ credit-deposit ratio

NSDP = per capita net state domestic product

$\mathrm{GR}=$ growth rate

$\mathrm{NOF}=$ number of factories

Financial inclusion (FID), the dependent variable is the number of deposit accounts (not the amount) in

\footnotetext{
${ }^{6} 30$ regions times 5 years $=150$
}

each state which is a total sum of number of savings account, current account and term accounts in each state. The rationale behind this is that the more the number of accounts, more will be the financial inclusion. Focus is therefore, on the rate of inclusion as per accounts as a measure of breadth rather than the amount as a measure of depth given that such amount distribution may be largely susceptible to outliers. Considering the same notion Sarma [8] considered bank accounts per capita as a signifier of the penetration of banking system. A similar indicator is taken by Kumar [9] in his study that also sought to identify the determinants of financial inclusion in India.

In the recent years, the Reserve Bank of India (RBI) has made several attempts at improving the branching network and as well as banking convenience for all by taking various initiatives. As such, banks have had to broaden their branch networking across the various states in India. Number of banking centres (BC) or bank branches in every state has been included as an independent variable and have previously also been used by various researchers [4]. The World Bank [10]; and Burgees and Pande [11] in their various financial inclusion studies also used access to and density of bank branches as a determinant of financial inclusion. It is expected that a positive relationship between $\mathrm{BC}$ and the dependent variable, FID would be obtained.

The number of male and female account holders has been incorporated to analyse the impact of gender on financial inclusion. As argued by Adewale, Mustafa, and Salami [1], there is no statistically significance moderating effect of gender on financial exclusion in their study on Ilorin, Nigeria. As such, they opine that the deliberate target of the financial inclusion strategies like micro-finance towards the women would only aggravate the incidence of financial exclusion of the males. However, a World Bank report [10] states that there is greater poverty, slower economy and weaker governance in the countries and societies that discriminate on the basis of gender. Even though the microfinance programmes in India are making efforts but little can be known whether the outcome of these programmes actually help in attaining financial inclusion for women. It is 
thus envisaged that using the males as a reference group, a positive relationship is expected between Male Access to Credit (MAC) and FID as indicators of number of male account holders and financial inclusion respectively.

Another exogenous variable used is the amount of outstanding credit in the scheduled commercial banks. This is because of the fact that the higher the outstanding credit in the banking system, higher will be the number of people financially included. Therefore, more number of loans implies higher access to finance by the people denotes more people in the financial included circle and thus we expect this variable to have a positive impact on our dependent variable. Similarly, Credit-deposit ratio which is a measurement for proportion of loan assets created by banks from the deposits received is also included as a likely determinant of financial inclusion in India. Having high ratios for credit deposits depicts greater banking and investment activities [12][10].

To understand the effect of the net state domestic product on the banking penetration system and the overall financial inclusion we have incorporated the per capita net state domestic product to assess what influence the states' economic and monetary position has on the banking penetration system. A similar estimate has been taken by Nitin Kumar [9] while assessing the determinants of financial inclusion in India. Quite similar to the above mentioned is the growth rate of the states measured as the volume of all the goods and services produced within the state in a certain time.

The rationale behind using this as a variable is quite similar to the one mentioned above, in which case we assume that the higher the growth rate in the states, higher should be the chances of the people being financially included. The importance of industrialisation on achieving financial inclusion is evidently seen in the previous literature. For this reason the number of factories in each state as a proxy for industrialization which is obtained from the Annual Survey of Industries (ASI) is included. This proxy is used as yearly data given that at the state level in India, data on employment could not be obtained because the census in India comes out in every 10 years. Likewise people with more economically secure status are more likely to be financially included [13]. Therefore we assume industrialisation to predict the level of employment especially with respect to lower and middle class income groups and have henceforth taken the number of factories as a proxy.

\section{Tools of Statistical Analysis}

As panel data provides information on individual behaviour both across individuals and over time; therefore, it covers both cross-sectional and time series dimension. That is, $\mathrm{N}$ individuals observed at $\mathrm{T}$ regular time periods. $4 \mathrm{~A}$ balanced panel data in which the number of observations for every variable and every individual is same $(\mathrm{Ti}=\mathrm{T}$ for all $\mathrm{i})$ is used in this study due to availability of data and the relative ease of statistical operations and assumptions compared to the unbalanced panel data.

The most important assumption of the panel data analysis according to Asteriou and Hall [14] is the pooling assumption which assumes all individual relationships have the same parameters. A common set of parameters is imposed across individuals that have been pooled together into one data set. The pooling assumption however has some pros and cons. Biased estimates in a single individual regression which is caused due to omitted variables doesn't exist in the context of panel data. However, if the pooling assumption is not true in the heterogeneous panel, the panel estimator would be expected to reveal a representative average estimate of the individual parameters. In such a scenario, the panel techniques are not very efficient and hence provide quite biased results. Furthermore, it is problematic to get significant t-ratios and Fstatistics when we have few observations while estimating samples. This is a problem generally faced with time series estimations and therefore the way to curb this problem is by pooling the data into a panel of time series from different cross-sectional units. By including dummy variables differences in various cross sectional and time series observations is generated by pooling data. Systematic differences are captured from panel assumptions with the help of

\footnotetext{
${ }^{4}$ The use of both $i$ and $t$ subscripts which are originally used for crosssectional and time series data, respectively are included in panel data.
} 
these dummies which is mostly termed as the fixed effect model and another alternate method is termed as the random effect model. In order to permit easy relative assessment of results obtained, the natural $\log$ of the variables mentioned above was generated and used in subsequent analysis.

FINDINGS, ANALYSIS AND DISCUSSION

\section{Findings}

We test the various constituent components affecting the number of deposits over 5 years. The basic empirical model for determining the factors affecting financial inclusion is mentioned in equation (1) above. The descriptive statistics of the data samples are provided in Table 1 .

Table 1: Descriptive Statistics

\begin{tabular}{|l|c|c|c|c|c|c|c|c|c|}
\hline Variable & Lfid & Lbc & Imac & Ifac & Loc & Icdr & Insdp & Lgr & Inof \\
\hline Mean & 7.508 & 6.179 & 7.983 & 7.009 & 11.789 & 4.017 & 10.583 & 2.010 & 7.541 \\
\hline Std. Dev & 2.892 & 1.721 & 2.529 & 2.348 & 2.395 & 0.437 & 0.538 & 0.487 & 1.958 \\
\hline Variance & 8.361 & 2.962 & 6.398 & 5.513 & 5.734 & 0.191 & 0.289 & 0.237 & 3.836 \\
\hline Skewness & -0.370 & -0.672 & -0.823 & -0.504 & -0.264 & 0.122 & -0.018 & -0.134 & -0.675 \\
\hline Kurtosis & 2.203 & 2.134 & 2.991 & 2.205 & 2.473 & 1.944 & 2.564 & 7.879 & 2.648 \\
\hline Obs & 150 & 150 & 150 & 150 & 150 & 150 & 150 & 148 & 150 \\
\hline $\begin{array}{l}\text { Sum of } \\
\text { wgt }\end{array}$ & 150 & 150 & 150 & 150 & 150 & 150 & 1501 & 150 & 150 \\
\hline
\end{tabular}

lcdr has the least standard deviation 0.4371 indicating minimum spread from its mean whereas the variable lmac has a comparatively larger standard deviation of 2.5294 . The variance however also measures the dispersion of the data from the mean. The variables in this dataset are platykurtic except for lgr (growth rate) which is extensively leptokurtic. Also, all variables except lcdr are negatively skewed, though possessing values not far from 0 .

\section{Panel Data Analysis}

Since operating data ranges over several orders of magnitude, $\log$ transformation is required as a measure of exploratory data analysis. After transforming the variables into logs, we declare the panel structure of our data. As our data is balanced we proceed with our first OLS regression. However, to test whether Generalized Least Squares is essential or simple OLS would suffice, further assessment is required.
After obtaining the estimates of the OLS model, we contrast between the OLS and random effect by utilizing Breusch and Pagan test. The ascertained quality surpasses the classified chi-squared estimate. So we presume that the arbitrary impact is more suitable than the pooled OLS model, and as such, the GLS method is essential. 
Table 2: Breush and Pagan Langrarian multiplier test

\begin{tabular}{|c|c|}
\hline chi2(1) & 73.62 \\
\hline Prob > chi2 & 0.0000 \\
\hline
\end{tabular}

Since the calculated value exceeds the tabulated chisquared value, we conclude that the random effects are appropriate than the pooled OLS model. Moreover, it also depicts there are state-specific effects in our data. If the state-specific effects are uncorrelated with the regressors, a consistent estimator will be delivered by the random effect estimator which is also efficient.

To check for heterogeneity in our data or individuality among the states we use the fixed effects model that allows the states to have their own intercept value. Outstanding credit and number of factories again prove to be significant and having positive impacts on the proxy of financial inclusion. However, to verify whether fixed effects model is the appropriate model or we stick to random effects model, we make use of the Hausman test which detects the best suitable method to be applied.

$\mathrm{H} 0: \operatorname{Cov}(\alpha 1, \mathrm{xit})=0$ (Random Effect)

$\mathrm{HA}: \operatorname{Cov}(\alpha 1, \mathrm{xit}) \neq 0$ (Fixed Effect)

Since the Hausman statistic is too large (73.63) and the p-value is too small we reject the null hypothesis that says the random effects model to be appropriate and accept the alternative hypothesis and consider the fixed effects model to be the most suitable method for our study.

As after running the Hausman test, we find the fixed effect model to be the most suitable for our study, we further test if time effects are needed to run the fixed effect model. We reject the null hypothesis as all year's coefficients are jointly significant, thus time fixed effect assessment is needed in this study. We also test for the state effects in the fixed effect model. The results obtained are the same as that in the time fixed effect model. From there, we conclude that we reject the null hypothesis of having common intercept for all the states in India included in our study.

Obtaining the fixed effect model as the most suitable for our study makes economic sense. Taking into consideration the state-specific effects reflecting initial technological and resource endowments, economic conditions, climate, institutions, culture, and so on, that differ across all the states in India, therefore it can be clearly argued that these are likely to be correlated with the outstanding credit, number of factories, bank branches etc. in the various states.

Table 3: Results of Panel data analysis

\begin{tabular}{|c|c|c|c|}
\hline & Pooled OLS & Random effect & Fixed effect \\
\hline \multirow{2}{*}{ Constant } & 1.34 & 0.98 & -24.84 \\
& $(0.56)$ & $(0.69)$ & $(-5.02)$ \\
\hline \multirow{2}{*}{ In BC } & 0.13 & 0.2962247 & -0.6536805 \\
& $(2.03)^{* *}$ & $(2.11)^{* *}$ & $(-1.08)$ \\
\hline \multirow{2}{*}{ In MAC } & .0188568 & 0.0093032 & -0.0571081 \\
& $(0.20)$ & $(0.11)$ & $(-1.20)$ \\
\hline \multirow{2}{*}{ In FAC } & .0129119 & -0.0037972 & -0.0478373 \\
& $(0.13)$ & $(-0.04)$ & $(-0.99)$ \\
\hline \multirow{2}{*}{ In OC } & 1.561162 & 1.643023 & 1.647579 \\
& $(23.75)^{* * *}$ & $(27.25)^{* * *}$ & $(36.41)^{* * *}$ \\
\hline \multirow{2}{*}{ In CDR } & -1.521083 & 1.574927 & -0.426399 \\
& $(-6.55)^{* * *}$ & $(-6.48)^{* * *}$ & $(-1.24)$ \\
\hline
\end{tabular}




\begin{tabular}{|c|c|c|c|}
\hline In NSDP & $\begin{array}{c}-.3065726 \\
(-1.50)\end{array}$ & $\begin{array}{c}-0.2876561 \\
(-1.32)\end{array}$ & $\begin{array}{c}0.9064265 \\
(1.62)\end{array}$ \\
\hline In GR & $\begin{array}{c}.0841062 \\
(0.59)\end{array}$ & $\begin{array}{c}0.0550815 \\
(0.41)\end{array}$ & $\begin{array}{c}-0.0449515 \\
(-0.58)\end{array}$ \\
\hline In NOF & $\begin{array}{r}-.6567829 \\
(-5.28) * * *\end{array}$ & $\begin{array}{r}-0.7251883 \\
(-5.57) * * *\end{array}$ & $\begin{array}{r}1.315544 \\
(3.74)^{* * *}\end{array}$ \\
\hline $\begin{array}{l}\text { Breush-Pagan LM } \\
\text { Test } \\
\end{array}$ & \multicolumn{2}{|c|}{$\begin{array}{c}73.63 \\
(0.0000) \\
\end{array}$} & \\
\hline Hausman Test & & \multicolumn{2}{|c|}{$\begin{array}{c}59.67 \\
(0.0000)\end{array}$} \\
\hline Observations & 148 & 148 & 148 \\
\hline $\begin{array}{l}\text { Heteroscedasticity } \\
\qquad\left(\chi^{2}-\text { stat }\right)\end{array}$ & & & $\begin{array}{l}1603.43 \\
(0.0000)\end{array}$ \\
\hline $\begin{array}{l}\text { Multicollinearity } \\
\text { (vif) }\end{array}$ & & & 7.81 \\
\hline $\begin{array}{c}\text { Serial Correlation } \\
\text { (F-stat) }\end{array}$ & & & $\begin{array}{c}67.816 \\
(0.0000)\end{array}$ \\
\hline
\end{tabular}

Figures in the parenthesis are t-statistics, except for Breusch-Pagan LM test, Hausman test,

Heteroscedasticity and Serial Correlation, which are p-values. *** sig. at 0.01, **sig at 0.05 .

Estimation results of our panel data for all the indicators using the three methods (OLS method, random effects and fixed effects) are tabulated in the table shown above.

Considering that the gender perspective does not deliver the desired results, however it is quite clear from the raw data that the number of female accounts are much lower than the male accounts. Microfinance programs which are launched by the Central Government or NABARD, in such a case may prove to be quite fruitful for the women as it can improve economic equality and can assist in alleviating poverty. Taking initiatives such as educating women about the financial dealings may help them become financially independent and become a part of the financially included group in the society. Swamy [15] in his study which tries to explore the importance gender has on a borrower in terms of accessing finance found that the financial inclusion programs undoubtedly impact the lives of women especially in the rural areas and helps in improving their standard of living to a decent level.

Outstanding credit seems to have a positive impact on financial inclusion in all the three models. The results obtained are very significant with t-statistics obtained more than 20 on average for all the models. Therefore, higher the amount of outstanding credit, higher will be the financial inclusion. This however, has certain drawbacks as the amount of interest to be paid on such credit usually creates the vicious cycle of debt for the rural people. As one of the reasons attached to the alarming rate of suicides among Indian farmers are the high debt burdens, thus interest rates on such credit must be made affordable for such people as $50 \%$ of the agricultural households are in debt.

Higher banking and investment activities could also be predicted with the help of credit-deposit ratio. The higher the ratio, higher is the expected financial inclusion. However, the fixed effect model does not exhibit credit-deposit ratio as a significant variable. But as far as the other two models are concerned, it has positive impact on the proxy of financial inclusion. Therefore, we may partially agree with Beck et.al [16] regarding the significance of this ratio regarding progressive banking penetration considering the Indian states.

Moreover, proportion of factories which may be taken as a proxy for industrialization or employee base is also found to be a very significant 
determinant for attaining financial inclusion in Indian states. According to Devlin [13], people having more secure status are not expected to be financially excluded. Therefore, considering this notion we believe that higher the number of factories in the states in India, higher will be the financial inclusion.

\section{DISCUSSION}

As India is a very diverse country, each state differs from the other with respect to many factors like education, employment, economic conditions, culture and languages. In such a case, comparing a state like Kerala which has more than $90 \%$ literacy rate with that of Bihar which has a comparatively low literacy rate may not yield similar outcome. Hence as indicated in our results, it is quite evident that a state like Kerala is more financially included than Bihar. An outcome like this offers justification for why this research is not conducted on a general country basis but rather considers all the different states in India, keeping in mind that each state has its own unique characteristics and different economic conditions.

The Indian economy is growing at a very fast pace and India is aiming to become an economic behemoth in the years to come. In such a scenario, equitable distribution of wealth attained by its populace is necessary along with inclusive growth that would have been achieved to reach the objective. Therefore, it is important that appropriate financial services are made available to every individual across the country to make sure that the gap between the rich and the poor is diminished and each individual contributes to the success and growth of the country.

Thus, when it comes to outstanding credit, our study is in line with all the major studies being carried out towards financial inclusion. Outstanding credit is considered as the most crucial variable for bringing the country inside the circle of financial inclusion. However, there are certain limitations attached to it, the main being the high loan repayment rates which makes it difficult for the poor and underprivileged to get access to financial services and the high interest rate charged by money lenders make them further indebted especially for the farmers and the rural people. If such a situation is followed by bad weather conditions like a drought, there are high chances of suicide attempts among such community. To curb this menace, it is very important for the authorities to charge affordable interest rates and the organizations like NABARD5 must come up with newer innovative programs specially designed to come up with solutions for such people and address their problems. Credit counselling for such prospects can prove to be quite beneficial for repayment of loans. In this area, India is still lacking behind and a lot more emphasis is needed to solve the problem of exclusion.

Other socioeconomic factors like income, literacy, inequality, physical access, and technology are also some important factors which are significantly associated with financial inclusion. Due to unavailability of sufficient data however, literacy could be included in our study though we strictly believe that literacy rate has a direct relationship with financial inclusion. Schemes and initiatives to educate the masses about financial literacy has proved quite favorable in the situation to handle exclusion. As for income and employment we have used the number of factories as the proxy for industrialization. Assuming that most of the lower middle class is associated directly or indirectly with factories therefore higher the number of factories, higher will be the employment ratio among such class and more will be the financial inclusion. This in fact is beneficial to the general economy of the country as a whole too. Therefore, schemes that generate employment have various benefits as it does not only help in eradicating poverty but also improves the income level and improvement towards the overall financial inclusion.

\footnotetext{
${ }^{5}$ NABARD- National Bank for Agriculture and Rural Development
} 


\section{CONCLUSION}

This study provides the empirical analysis of the factors that influence financial inclusion in the Indian states. It includes annual information of about 26 states and 4 union territories in India for a period of 5 years from 2009 to 2013.The results suggest that there exists specific state effects among our data. Expectedly, each state in India is different from the others in terms of major factors like education, income level, employment, culture and even languages. For that reason these state specific effects are observed in our data. Furthermore, outstanding credit and the number of factories both have positive impact on financial inclusion, which implies that with more credit being made available to the unserved population, more people will be able to move in the circle of financial inclusion. Likewise, higher number of factories and greater industrialization will also promote financial inclusion by means of providing jobs to the unemployed and with some income in hand, more people can have access to the financial facilities and benefit from them accordingly.

Moreover, the necessary initiatives taken by the RBI and the Government of India have proved to be quite fruitful towards the attainment of financial inclusion over the years. As the problem of exclusion is faced worldwide and many different models are being proposed by various countries to tackle it, studies even show that more than $70 \%$ of the adult population in the emerging markets is unable to benefit from the banking services. Therefore, a lot more needs to be done in this regard especially when it comes to a developing country like India which has a huge potential for microfinance.

By adopting a multi-pronged approach till now India has improved a lot compared to the previous years when it comes to tackling the issue of financial exclusion. But considering the huge size of India with its enormous population and diverse culture and norms, state-wise initiatives must be undertaken apart from the initiatives taken by the Central government as a whole to curb the problem of financial exclusion.

\section{REFERENCES}

[1] Adewale.A., Mustafa. D, and Salami. L (2013). A Second-Order Factor Gender- Measurement Invariance Analysis of Financial Exclusion in Ilorin, Nigeria. ITJEF 2013 Vol.4(6): 398-402 ISSN : 2010-023X

[2] Leyshon A. and Thrift. N. (1995) Geographies of Financial Exclusion: Financial Abandonment in Britain and the United States Transactions of the Institute of British Geographers, New series, 20(3): 312-41

[3] Sinclair, P.S. (2001) Financial Exclusion: An Introductory Survey. Centre for Research in Socially Inclusive Services (CRISIS), Heriot-Watt University, Edinburgh.

[4] Leeladhar, V.(2006). Taking banking services to the common man- Financial Inclusion, Reserve Bank of India Bulletin, Mumbai

[5] Subbarao, D. (2009a). Financial Inclusion challenges and opportunities. Speech delivered by Dr. Duvvuri Subarao, Governor, Reserve Bank of India. Bankers club Kolkata December 9

[6] Subbarao, D. (2009b). Should banking be made boring? An Indian perspective. Keynote address by Dr. Duvvuri Subarao, Governor, Reserve Bank of India. International Banking and Finance Conference, Mumbai, India, November 25.

[7] Kapoor.A (2014). Financial Inclusion and the future of Indian economy. Futures 56. (35-42)

[8] Sarma, M. (2008). Index of financial inclusion. Working paper 215, Indian Council for Research on International Economic Relations.

[9] Kumar, N. (2013). Financial Inclusion and its determinants: evidence from India. Reserve Bank of India, India. Journal of Financial Economic Policy Vol. 5 No.1, 2013. pp.4-19

[10] (The) World Bank (2008a), Banking the Poor:

Measuring Banking Access in 54 Economies

[11] Burgess, R., \& Pande, R. (2005). Do rural banks matter? Evidence from the Indian social banking experiment. American Economic Review, 95(3), 780-795.

[12] Beck, T., 2008. The econometrics of finance and growth. Policy Research Working Paper No. 4608, The World Bank.

[13] Devlin, J.F. (2005), "A detailed study of financial exclusion in the UK", Journal of Consumer Policy, Vol. 28, pp. 75-108.

[14] Asteriou, D. and SG Hall (2011), Applied Econometrics, 2nd ed., Palgrave-McMillan.

[15] Swamy. V (2014). Financial Inclusion, Gender Dimension and Economic Impact. World Development.Vol 36 pp, 1-15 
Mansha/ International Journal of Business Management, 3(6) 2019, Pages: 23-32

[16] Beck, T., Demirgu"c_-Kunt, A., \& Levine, R. (2007). Finance, inequality, and the poor. Journal

Economic Growth, 12, 27-49. of 